\title{
How can the information system be directed to contribute to the overall performance of administrations Status of Moroccan Universities
}

\author{
Ayoub Gacim ${ }^{1}$, Hicham Drissi ${ }^{2}$, Mohamed Azzouazi ${ }^{1}$ \\ ${ }^{1}$ Laboratory of Information Technology and Modeling (LTIM), Hassan II University, Faculty of Sciences Ben M'SIK Casablanca \\ ${ }^{2}$ Laboratory of Research and Prospects in Finance and Management (LRPFG), Hassan II University, National School of business and \\ Management of Casablanca
}

\begin{tabular}{|c|c|}
\hline Article Info & ABSTRACT \\
\hline Received Sep 5, 2018 & $\begin{array}{l}\text { An information system necessarily has a mode of governance. Whatever } \\
\text { their nature, there are rules applying to this system. And control } \\
\text { mechanisms are usually in place. Thus, it is not a question of creating the } \\
\text { governance of the information system, but really about making it a tool of } \\
\text { management and improvement. }\end{array}$ \\
\hline $\begin{array}{l}\text { Keyword: } \\
\text { Governance information } \\
\text { system } \\
\text { Reference system } \\
\text { Maturity evaluation } \\
\text { Information technology }\end{array}$ & $\begin{array}{l}\text { When ranking countries on the e-government scale, Morocco ranks } 140 \text { out } \\
\text { of } 192 \text { UN member states. Yet Morocco had introduced computers in the } \\
\text { administration since the early } 60 \text { s. This ranking, which illustrates the delay } \\
\text { by the computer in the Moroccan administration, and therefore the } \\
\text { difficulties that Morocco encounters in the improvement performance of its } \\
\text { administration, should it not be attributed to a deficit in public management } \\
\text { of information systems? }\end{array}$ \\
\hline University & $\begin{array}{l}\text { The objective of this article is to evaluate the management of information } \\
\text { systems in Moroccan public administrations and specifically to dissect the } \\
\text { profile of Moroccan universities. }\end{array}$ \\
\hline
\end{tabular}

\section{Corresponding Author:}

Azzouazi Mohamed

Laboratory of Information Technology and Modeling (LTIM), Hassan II University, Faculty of Sciences Ben M'SIK Casablanca

Faculté des Sciences Ben M’SikAV Driss El Harti, B.P 7955, Sidi Othmane, Casablanca,MAROC.

Email: azouazii@gmail.com

\section{Introduction (11 PT)}

The purpose of this article is to verify the premise that the implementation of the approach and management tools of the information system is a very important issue and has a significant impact on the governance and performance not only of the information system and the whole organization (Moroccan universities).

The other objective is to assess the maturity of the information system orientation function in Moroccan universities, through a specific model and an interview manual adapted to the context of public administration in the context of a project proposal. Mathematical model of multicriterion rule.

[1]Information systems management is an emerging concept that tends to impose itself in a changing economic environment. This period leads to some extent to opposing positions because of difficulties in understanding some of its principles.

However, it can not be denied that the questions posed by "information system governance" or "IT governance" are certainly good questions, and key questions for the smooth functioning of the information 
system, see the importance of the information system issues in the organization and the effectiveness of its management.

The first point of the problem: Can the proposal for a multi-terminal model be used to improve the management of the information system in Moroccan universities?

The second point of the problem: evaluation of the organization's information system, how reliable and objective is this self-assessment approach?

\section{Objective}

[2] To verify the hypothesis according to which, the implementation of an information systemmanagementapproach constitutes a very important stake and a major impact on the governance and the performance not only of the information system but also of any the university organization.

The purpose of this research is to evaluate the maturity of the steering function of the information system of Moroccan universities, through a qualitative study by mobilizing a specific model and interview guide adapted to the context of the Moroccan university. by proposing a mathematical model of multi-criteria judgment "MACBETH".

In the context of public administration, the answer to the research problem is of great difficulty, because of the various perceptions of overly specialized emerging concepts with the new technologies and the governance of information systems, we propose an analysis the SI Pilot's performance in the context of a cross-model model entitled: "3P vs. 3E": Platforms, Professionals, Process vs Efficiency, Efficiency, Economy with a frame of reference for the processes resulting from good practices

[3]The steering of the performance of the computer industry, return to pilot the three factors of production of the information namely:

- Technical platforms or IT systems

- Business processes

- Skills or professionals

[4] These three elements are the pillars of a well-functioning information system, with regard to the categories of activity objectives mentioned above:

- Availability

- Integrity

- Privacy

- $\quad$ screening (traceability)

- Compliance

- Efficiency

\section{Psotionig the search}

[5\&6]This approach is then interpretative-constructivist. Interpretative in the sense that it uses the arrangement between two modeling approaches, as well as a field investigation for the determination of IS performance criteria in Moroccan universities. Subsequently a tree modeling of these performance criteria according to the above model 3E-3P presented, these on one hand. On the other hand, the constructivist aspect of this work stands out in mathematical modeling, MACBETH in essence and the results will be explained below. To provide a tool for reconstructing the reality of measuring the overall performance of IS in Moroccan universities. Modeling proposal is to explain the overall performance in three areas (technical, professional and process). Subsequently articulate these with the contributions and knowledge of the literature on the overall performance of IS.

\section{SI Pilot Performance AnalysisModels: 3P / 3E Conception model}

[7\&8] These categories of objectives include specific objectives for each of the 3Ps, and can be measured by a series of Key Goal Indicators, defining the goal to be achieved, which are accompanied by a set of Key 
Performance Indicators (KPIs), defining the degree of achievement of objectives, as shown in the following diagram for IT processes.

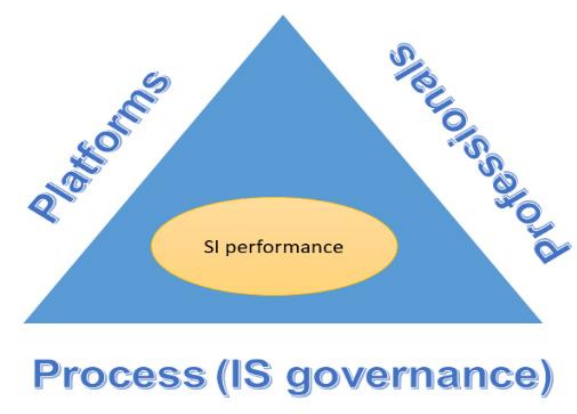

Figure 1: The triangle 3P of an SI

These indicators can be optimized to improve and serve the "3E": Efficiency, Efficacite, Economy constituting the performance of the information system to Moroccan universities, and if in addition, the objectives of the information system are in alignment with the strategic objectives universities, these 3Ps contribute independently to the golden triangle of the university's overall performance (see following diagram).

At the level of Moroccan universities, we note the absence of a system of relevant objectives and the elements of edges necessary for steering, in addition to a real industrialization of the production of information and services, the steering of the IT still has a way to become professional.

\section{Objectives}

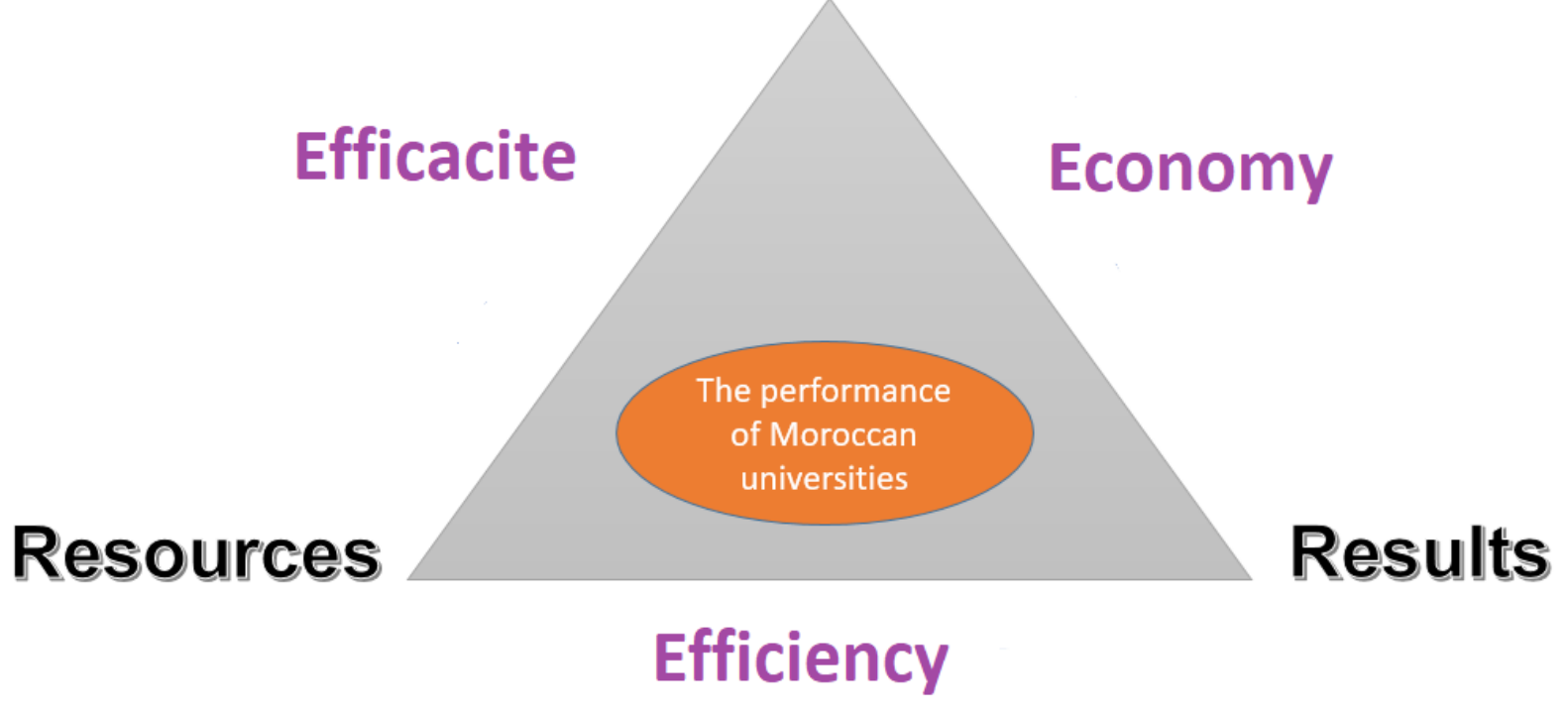

Figure 2: Golden Triangle of Performance Management

\section{Conclusion}

In a national context of governance, the missions of the Moroccan university are multiplied. To achieve this, several elements must interact by using modern devices. 
Based on the crossed model mobilized in this work, we can conclude that the overall performance of Moroccan universities will pass through the establishment of an information system adequate to its specificity, it will have a positive impact in its governance.

This managerial practice will help strategic decision-making by accessing reliable and real-time data, by editing different dashboards. It is an observation and description tool that aims, from management data and / or statistics, to give university managers a real vision on the different business processes. The Information System put in place will push to modernize the governance of Moroccan universities

We can also conclude that with the technological revolution and in a context of national governance playing on the issue of sustainable development, the main contribution of IS is to have maintained the dynamic of collaboration between all Moroccan universities to build a coherent national information system.

\section{References}

[1] Claude Alazare: « Management control and information system » $\mathrm{P}$ 65-70

[2] Bana e Costa C.A. and J.C. Vansnick. MACBETH: An Interactive Path Towards the Construction of Cardinal Value Functions. International Transactions in Operational Research, 1(4):387-500, 1994

[3] COBIT, ITIL, ISO 27001...

[4] IT Gouvernance: IT Management for business Managers, Professional Practice Reference Collection AFAI et CIGREF (IGSI) 2004

[5] S. Muthubalaji , R. Anand and, N.karuppiah Periodicals of Engineering and Natural Sciences ISSN 23034521 Vol.6, No.2, December 2018, pp. 283 294

[6] Luige Vladareanu, Ramona Lile, Mihai Radulescu, Daniel Mitroi , Doina Marin, Alexandra Catalina Ciocîrlan , Elena Corina Boscoianu , Mircea Boscoianu Periodicals of Engineering and Natural Sciences ISSN 2303-4521 Vol. 7, No. 1, June 2019, pp.324-329

[7] FatimazahraBentaleb; CharifMabrouki\&AlamiSemma (2015) A Multi-Criteria Approach for Risk Assessment of Dry Port-Seaport System, Supply Chain Forum: An International Journal, 16:4, 32-49.

[8] Türker TUNCER Periodicals of Engineering and Natural Scinces ISSN 2303-4521 Vol.5, No.2, October 2018, pp. 1 9 